\title{
Indios, soldados sin patria: la conscripción militar en el Perú durante el siglo XIX
}

\author{
Indians, soldiers without homeland: military conscription in Peru \\ during the $19^{\text {th }}$ century
}

David Víctor Velásquez Silva

Universidad de Lima

\section{RESUMEN}

El presente artículo busca explorar la historia de la conscripción militar en el Perú durante el siglo xIx y su relación con la población indígena. La idea central gira en torno a las dificultades del Estado peruano para construir un sistema de conscripción verdaderamente nacional que incorpore universalmente a las filas del Ejército a los ciudadanos en edad de servir. En ese sentido, se pasa revista a los procedimientos que a través de la violencia y la negociación emplearon los caudillos decimonónicos para proveerse combatientes en un ambiente de constantes golpes de Estado y revoluciones, así también a los intentos de reforma que se realizaron hasta fines de la centuria. En esta historia, resulta evidente que el deber ciudadano de portar las armas recayó fundamentalmente en la población campesina indígena, mayoritaria en el país, la cual contaba con débiles relaciones de autoridad con el Estado central, lo que daba como resultado —paradójicamente - tenues relaciones de ciudadanía. Obligados a servir o negociando su participación en la guerra, fueron estos, ciudadanos sin patria.

\section{Palabras clave:}

conscripción militar, indígenas, Ejército peruano, leva, ciudadanía
ABSTRACT:

This article seeks to explore the history of military conscription in Peru during the $19^{\text {th }}$ century and its relationship with the indigenous population. The main idea focus on the difficulties of the Peruvian State to build a truly national conscription system that universally incorporates citizens of service age into the ranks of the Army. In this sense, we review the procedures used by the 19th century caudillos, through violence and negotiation, to gather combatants in an atmosphere of constant coups d'état and revolutions, as well as the reform attempts carried out until the end of the century. In this story, it is evident that citizen's duty to carry arms fell mainly on the indigenous peasant population, which accounted for the majority in the country and had weak relations of authority with the central state, resulting - paradoxically - in tenuous relations of citizenship. These citizens without a fatherland were obliged to serve or negotiate their participation in the war.

Keywords:

military conscription, indigenous people, Peruvian army, levy, citizenship 


\section{Introducción}

E proceso de construcción del Perú como Estado y como nación ha sido y es un proceso difícil y a veces tortuoso. Al cabo de casi doscientos años de existencia como república independiente, en nuestro país aún existen inequidades - llamadas hoy brechas - que manifiestan el acceso diferenciado a derechos que la República prometió universalmente a sus ciudadanos desde su fundación. Requisito fundamental para que esta promesa se cumpla y logremos ser un país moderno y justo es que el Estado - por medio de sus múltiples instituciones - cree las condiciones para que todos los ciudadanos, sin excepción, accedan a los derechos que garantiza y haga cumplir los deberes que también el ejercicio de la ciudadanía exige. Solo así seremos la nación (cívica) prometida en la auroral república.

En este artículo, me propongo presentar un recorrido histórico de la relación del Estado republicano con un grupo distinguible de la población peruana decimonónica, la población indígena. Verifico esta relación por medio de uno de los deberes que asignó este nuevo Estado republicano a sus ciudadanos, a saber, el servicio en las filas del Ejército. Mi interés es contribuir al conocimiento de la ciudadanía en el Perú, en la dimensión de sus deberes, para poner de manifiesto las inequidades que históricamente se han sedimentado en el imaginario, haciéndolas invisibles hasta el punto que incluso casi doscientos años después de la Independencia, solo algunos ciudadanos cumplen con este deber ${ }^{1}$.

El argumento central de este artículo gira en torno de las dificultades del Estado peruano para construir un ejército nacional, haciendo extendido el cumplimiento del servicio militar a los ciudadanos durante el siglo xIx. Estas dificultades fueron producto de la debilidad del Estado de la postindependencia y del estado de guerra permanente que caracterizó las primeras décadas del periodo republicano. Un Estado con escasa penetración en el territorio y apremiado por la guerra recurrió a prácticas que combinarían la coerción y el consenso para asegurarse soldados, que, en su mayor parte, fueron indígenas. Desde otro punto de vista, el fracaso del cumplimiento del servicio militar como deber se debe comprender también como manifestación del rechazo de la población indígena a entregar parte de su reserva humana a una entidad ausente que no ofrecía derechos, sino beneficios esporádicos y como fruto de alianzas clientelares, es decir, ausencia de compromiso ciudadano de parte de esta población.

Durante la segunda mitad del siglo xIX, se hicieron diversos intentos por reformar estas formas de conscripción; sin embargo, resultaron insuficientes, pues, por un lado, prácticas como la leva se habían convertido en parte de la cultura militar decimonónica y, por otro, se encargó que los procedimientos para exigir universalmente un deber ciudadano fueran ejercidos por los notables locales, las élites privilegiadas, con casi nulo control del Estado central. Sin posibilidad práctica de modificar las formas de "conscripción" preexistentes, sobrevino la Guerra del Pacíico, la que demostró, con inexorable crueldad, las consecuencias de crear ejércitos a empujones o por negociaciones clientelares, llevando al campo de batalla a individuos —en su mayoría, indígenasque no contaban con vínculos afectivos con la causa por la que se luchaba, esto es, soldados sin patria.

Solo en el ambiente de regeneración del período de la posguerra y durante la República Aristocrática, en el tránsito del siglo xIx al xx, se dieron las condiciones para realizar reformas de profundidad que modificaron las inveteradas prácticas de la cultura militar decimonónica. Un Ejército reformado, con forma burocrática, reemplazó a los antiguos caudillos militares, extendiendo el radio de sus órdenes a gran parte del territorio nacional. El caso peruano mostraba con elocuencia que solo se podía cumplir un deber ciudadano, como el servicio militar, en tanto existiera un Estado como realidad concreta que se encargara de hacerlos cumplir. Para las élites de las postrimerías del siglo XIx, el servicio militar

1 Si bien es actualmente un tema olvidado, durante el primer semestre del 2013, se produjo una interesante polémica respecto de la aplicación del Reglamento (Decreto Legislativo 1146) de la ley vigente del servicio militar (2008). El debate giró en torno de la conveniencia y constitucionalidad de convertir en obligatorio el servicio militar cuando no se lograra la cantidad de altas suficientes de manera voluntaria. Uno de los argumentos en su contra giró en torno a que los jóvenes sobre quienes recaería este deber podrían ver interrumpidos sus estudios y afectar su proyecto de vida. El Tribunal Constitucional declaró inconstitucional este reglamento, restituyendo al servicio de las armas, como un acto facultativo; sin embargo, aún no deja de ser cierto que los ciudadanos que forman las filas del Ejército peruano, desde el siglo xIx hasta la fecha, siguen siendo aquellos que tienen menos recursos y, particularmente, los de rostro cobrizo. 
debía cumplir adicionalmente otra función: convertirse en un instrumento de civilización (occidentalización y ciudadanización) de la reluctante población indígena, que le permitiera formar parte de la nación peruana.

\section{La formación de ejércitos en la temprana República}

Al instituirse el Perú como República, la ciudadanía fue reconocida de manera igualitaria a todos los hombres (varones) libres y avecinados en las poblaciones de su territorio. Los requisitos legales para el acceso a la ciudadanía no eran insuperables para la mayoría de la población, gozando formalmente de este estatus la población indígena, mestiza y blanca. Ello rompía el ordenamiento colonial que reconocía la existencia de dos repúblicas, étnicamente diferenciadas (la de españoles y la de indios), a las que les correspondía cargas y privilegios. De acuerdo con las normas republicanas, el nuevo régimen otorgó a estos grupos étnicos el derecho ciudadano por excelencia, el sufragio, mientras que exigía de ellos dos deberes fundamentales: el pago de impuestos y la prestación del servicio militar. Los estudios sobre las elecciones y la tributación del Perú decimonónico han mostrado con claridad que, a pesar del auroral voluntarismo republicano por igualar formalmente a los ciudadanos, el ejercicio de la ciudadanía fue diferenciado en todo el siglo xIx, cabiéndole a la población indígena mayor peso en el cumplimiento de deberes y casi nulo reconocimiento de los derechos otorgados. En el caso de las elecciones, aunque los indígenas formalmente contaban con este derecho, y de hecho votaban, su participación fue inferior a la de otros grupos, estuvo mediatizada por las élites locales criollas y mestizas, y sus intereses sobre los cargos de elección disminuían a medida que los comicios se alejaban del nivel distrital, recayendo puestos de mayor jerarquía en otros grupos (Aljovín, 2005; Núñez, 2005; Chiaramonti, 2005; Del Águila, 2013). Mientras que, en el lado contributivo, la abolición del tributo indígena y su reemplazo por la contribución personal no trajo grandes modificaciones. Si bien esta capitación debía recaer sobre todos aquellos que no pagasen impuestos de otro tipo (al comercio o a la producción artesanal), la dificultad para cobrarlo a grupos no indígenas o las connivencias entre estos y los recaudadores dieron como resultado que la contribución personal fuese un impuesto que en la práctica solo recaía en los indígenas (Walker, 2004, pp. 238-243; Remy, 1988, pp. 463-476; Contreras, 2004, pp. 54-56).

Una situación similar sucedió con el servicio militar. En consonancia con el goce de la ciudadanía, las constituciones y las normas militares instituyeron como deber de la población empuñar las armas al llamado de la patria². De acuerdo con el Reglamento Orgánico del Ejército de 1827 (norma que reguló la conscripción hasta 1848), el llamamiento de soldados debía ser hecho por el Ejecutivo, al que le correspondía computar el número de hombres que debía otorgar a cada departamento sobre la base del padrón de electores (ciudadanos con derecho a voto). Hecho esto, correspondía a los gobernadores de los distritos o comisarios suyos la designación o señalamiento de los conscriptos, los cuales debían, a su turno, ser reunidos en la capital del departamento bajo la vigilancia de los prefectos. Respecto al señalamiento de los futuros soldados, la norma solo prescribía el orden de prioridad: primero, los solteros que no sean hijos de viudas o padres ancianos, y en segundo lugar, los hombres casados sin hijos, los casados hijos de viudas o padres ancianos y los estudiantes de una carrera de letras. Por el contrario, el Reglamento no prescribía un procedimiento por el cual el gobernador señalaría a los conscriptos (Decreto del 1 de enero de 1827), vacío que de hecho ofreció la posibilidad de infinitos abusos, sobre todo, en las poblaciones rurales.

El llamamiento se hacía a individuos iguales y abstractos, correspondiéndole a cualquier ciudadano cumplir este deber; sin embargo, lo cierto fue que la mayoría de la tropa de los ejércitos decimonónicos estuvo siempre compuesta por población indígena (Basadre, 2003, I, pp. 122-123). Si bien la población indígena era mayoritaria en el país ( $60 \%$ del total de acuerdo con el censo de 1793), "[n]o se ven caras blancas entre los soldados rasos, pues los jóvenes con ascendencia predominantemente europea son rápidamente promovidos a oficiales", mientras que "[p]ara el servicio en la infantería se eligen casi únicamente a indios o cholos", como afirmaba el sabio Ernest Middendorf (1973, p. 270).

2 La Constitución de 1823, artículo 180, prescribía que "[n]ingún peruano podrá excusarse del servicio militar, según y como fuere llamado por la ley", mientras que el artículo 6 del Reglamento Orgánico del Ejército de 1827 establecía que se debía escoger a los ciudadanos para el servicio de los "censos que sirven para la elección de diputados al cuerpo legislativo". 
Esta apremiante exigencia contrastaba con la renuencia constante de la población indígena campesina a derivar parte de su fuerza de trabajo hacia actividades no orientadas a la reproducción de sus comunidades. Ceder hombres para el ejército permanente implicaba su pérdida, en el mejor de los casos, temporal (sin que ello implicara una delimitación taxativa y real del tiempo de servicio) y, en el peor de los casos, la pérdida total de un hombre en edad productiva, sin recibir nada a cambio ${ }^{3}$. Para los indígenas, el agente que reclamaba este tributo de sangre, sea la patria o la República, no dejaba de ser una entidad abstracta y lejana que solo se materializaba esporádicamente, y a veces brutalmente, a través de las fuerzas militares beligerantes (como se verá más adelante), mediante los "cobradores [de impuestos] subalternos" y gobernadores que recorrían las comunidades y pagos dos veces al año (Contreras, 2004, pp. 54, 57-59) o por medio de prefectos y subprefectos radicados en las capitales del departamento y provincia de las cuales marchaban solo en ocasiones específicas como rebeliones o guerras internas. En las enormes distancias que separaban a las poblaciones rurales del Perú decimonónico, el Estado republicano y su régimen legal no eran más que una desconsoladora proclamación, mientras que la vida cotidiana se basaba en las normas tradicionales de las comunidades, sus acuerdos, negociaciones y conflictos esporádicos con las élites locales (especialmente, hacendados) que alternativamente jugaban como sus competidores e intermediarios con el Estado republicano. Era ciertamente el Estado peruano una entidad ausente del campo, fenómeno que dará nacimiento al gamonalismo (Flores Galindo, 2008 [1988], pp. 247, 262-266). Sin una burocracia propia con capacidad de penetración en el territorio, resultaba casi imposible que las poblaciones indígenas pudieran establecer una relación de autoridad directa con aquel (es decir, una relación de ciudadanía) y al cual las comunidades pudieran reclamar una contraprestación o recibir una compensación por la cesión de su reserva humana para el Ejército. Solo así se puede comprender la resistencia de las poblaciones indígenas al servicio en el Ejército.
En ese contexto, no resulta extraño entonces que la forma más común que encontraron los caudillos para vencer la resistencia indígena y proveer a los ejércitos peruanos de soldados fuera el uso de la fuerza, es decir, la leva. Llamada en el siglo xix reclutamiento, fue un método compulsivo ejecutado por los propios cuerpos militares para reemplazar las constantes bajas de sus efectivos por deserción, enfermedad o muerte, y para aumentarlos en caso de guerra. Por lo general, el Gobierno solicitaba un número de soldados y correspondía al jefe de cuerpo llenarlo de la manera que las circunstancias (por lo general, de guerra) se lo permitieran ${ }^{4}$. La leva se realizaba desgajando patrullas de los cuerpos militares para desplegarlas en las poblaciones rurales en busca de hombres, los cuales eran tomados y dados de alta, sin más trámite que su reclusión en los cuarteles. Una descripción cruda de la leva la dio el viajero francés Sartiges (2012), quien presenció en 1834 uno de estos procedimientos en el departamento de Puno:

\begin{abstract}
Se les cortaba los cabellos y se les abría las orejas para reconocerlos y fusilarlos en caso de deserción. Los conscriptos eran encerrados en una iglesia transformada en cuartel donde no salían más que para hacer ejercicios dos veces al día. (p. 45)
\end{abstract}

Debido al carácter violento del reclutamiento, la conducción de las tropas levadas se hacía con las precauciones necesarias para evitar la deserción: en 1828, el prefecto de Ayacucho, Pío Tristán, tuvo que tomar varias providencias para impedir la fuga de sus tropas mientras las dirigía a la capital, como ordenar que los reclutas durmieran separados para evitar algún motín y solicitar el apoyo de los cuerpos de la Guardia Nacional de todos los poblados por donde pasasen (Aljovín, 2000, p. 168). La existencia de la leva mostraba la incapacidad administrativa y coercitiva del Estado para exigir el cumplimiento de este deber, respetando procedimientos que protegían las libertades y derechos que afirmaban asegurar las instituciones republicanas.

Sin embargo, la leva no era el único medio para conseguir hombres para los ejércitos caudillistas, pues

3 El general Domingo Nieto mencionaba en una de sus cartas de 1843, cómo la población indígena había desarrollado resistencias al reclutamiento o leva: "Se recluta en los pueblos sin reparo, se cometen extorsiones de todo género por los comisionados. Cada reclutamiento deja escuetos los pueblos y puebla las quebradas naturalmente desiertas y los montes por muchos días [cursivas del autor]" (Mc Evoy, 2015, t. I, p. 337).

4 En 1838, por orden del presidente Orbegoso, el general Nieto debía constituir un batallón, obligación de difícil cumplimiento, como lo afirmaba: "Ya no hay valor para sacar más reclutas de los pueblos, y me parece casi imposible que yo aumente la infantería hasta el número de mil seiscientas plazas, fuera de banda; estoy, sin embargo, haciendo los esfuerzos posibles por conseguirlo y cumplir con las órdenes..." (Mc Evoy, 2015, t. I, pp. 169-170). 
también existían medios voluntarios por los cuales se podía derivar la reserva de hombres indígenas a los caudillos militares. Dado que las guerras civiles o revoluciones fueron el medio más común por el cual diversas facciones políticas medían fuerzas para decidir su permanencia o acceso al poder, los bandos en liza buscaban movilizar la mayor cantidad de hombres posible para asegurar su victoria, razón por la cual, además de reclutar por la fuerza poblaciones, era común que los caudillos negociaran clientelarmente con los actores locales y regionales el acceso a la reserva humana disponible, especialmente, la indígena. En ese sentido, en contextos revolucionarios, los jefes militares pactaban clientelarmente alianzas con hacendados y comunidades indígenas la militarización de sus indios.

Diversos indicios para la primera mitad del siglo xix muestran la importancia del consenso. Por ejemplo, en 1835, el general gamarrista Miguel San Román logró constituir fuerzas militares con la población indígena de Lampa (Puno), prometiéndoles "la perspectiva seductora de tres días y tres noches de saqueo a raíz de la entrada en Arequipa" (Sartiges, 2012, p. 47; Tristán, 2005, p. 426). Voluntarios como estos que mostraban una acción destacada y leal para con sus oficiales eran recompensados con premios. Por ejemplo, Andrés de Santa Cruz creó un sistema de incentivos al enrolamiento que permitió un mayor control y estabilidad sobre sus tropas. El caudillo boliviano presionó a las autoridades locales para que otorgaran a los veteranos algunos topos cuando estos concluyeran su servicio, procurando, además, mantenerlos adecuadamente vestidos y remunerados puntualmente en dinero (Aljovín, 2000, p. 168).

La negociación fue especialmente importante para conseguir fuerzas auxiliares a los ejércitos regulares, las cuales asumían la forma de montoneras. Estas eran agrupaciones armadas irregulares que generalmente surgían de forma espontánea y aglutinaban a diversos grupos sociales que perseguían fines personales o reivindicaciones locales. En la costa, alrededor de ciudades importantes, las montoneras se dedicaban al bandolerismo y tenían un componente mayoritariamente negro y mestizo. En la sierra, eran principalmente indígenas y podían agrupar a los habitantes de pueblos y comunidades que se alzaban legitimadas por reivindicaciones locales, o formar parte de las huestes privadas de un hacendado local. El inicio de la guerra de independencia y las guerras caudillistas posteriores permitieron a estas bandas informales incorporarse a la política nacional, proporcionándoles un discurso ideológico y una agenda política. Negociaban su participación en las guerras a cambio de la satisfacción de sus propios intereses, siendo su concurso, a veces, decisivo en la victoria. Las montoneras serranas eran sumamente peligrosas para los ejércitos regulares, pues además de ser numerosas, nunca atacaban frontalmente: preferían lanzarse a la retaguardia o lanzar piedras o galgas desde los despeñaderos (Aljovín, 2000, pp. 166-167, 196-197; Quiroz, 1992, pp. 125-126).

Esta utilidad militar y política les permitió a varias comunidades indígenas negociar y obtener de los caudillos en liza los intereses corporativos de sus propias localidades. Los montoneros contaban con sus propios jefes, es decir, disponían de una autonomía desconocida para los indígenas incorporados a los ejércitos regulares, prestaban sus servicios solo durante el tiempo de la conflagración o el tiempo que las alianzas con los caudillos les fuera conveniente, a cambio de beneficios para la comunidad, como la exoneración de la contribución indígena, diezmos, o la elevación de jerarquía política de su población (Walker, 2004, pp. 283-310; Méndez, 2004; Chiaramonti, 2005, pp. 320-341). Este fue el caso de los iquichanos de Huanta, en la década de 1830, quienes se aliaron al presidente José Luis de Orbegoso en contra de Agustín Gamarra y Felipe Santiago Salaverry. En una carta del presidente a Tadeo Choque, jefe de los montoneros iquichanos, se le instaba a hostilizar a las tropas enemigas:

\begin{abstract}
Es preciso, pues, que usted aprobeche esta oportunidad, como lo está haciendo para atraerse la gratitud de sus conciudadanos, y hacerse acreedor de los premios que la Patria dispensa á los que le hacen servicios eminentes [cursivas del autor]. Debe V. usar del influjo que tiene entre sus paisanos para que obren activamente contra los sediciosos, impidiendoles las comunicaciones, privandolos de recursos y sorprendiendolos y atacandolos, de modo que no tengan reposo, mientras yo marcho con el Ejército que verá muy pronto. (Méndez, 2014, pp. 302-303)
\end{abstract}

En los casos en que los indígenas hacían prestación corporativa y voluntaria de hombres a los ejércitos caudillistas, estos no se comportaban como individuos-ciudadanos que respondían al cumplimiento de un deber abstracto nacido de los mandatos de su consciencia o de relaciones afectivas para con la nación o la patria. Por el contrario, ante la posibilidad de una contraprestación directa de beneficios por parte de los caudillos o sus representantes, los indígenas preferían derivar parte de sus hombres en contextos particulares, en tanto que la perspectiva de esa prestación fuera limitada en el tiempo, manteniendo su autonomía corporativa y buscando alcanzar fines también corporativos. 
Bajo este esquema general funcionaban los mecanismos de alistamiento de la población indígena en los ejércitos caudillistas: indígenas levados para componer las unidades regulares del Ejército propiamente dicho, indígenas enrolados ante beneficios fácticos y montoneros alistados clientelarmente. Sin embargo, para el Estado o su representación, los jefes militares, estos mecanismos tenían consecuencias estratégicas negativas para la guerra, pues un ejército constituido a empujones era volátil. La deserción era siempre una posibilidad que podía diezmar las filas antes o durante un combate. Así también, la cesión clientelar y esporádica de hombres era una forma poco estable, predecible y fiable para componer sus ejércitos: estas tropas y sus líderes no siempre seguían los mandatos de las autoridades militares; dirigiéndose por su propia agenda, ni decir sobre su lealtad. Si a ello se añaden situaciones harto frecuentes como el atraso o falta de paga, el abuso de los oficiales, el cambio de alianzas o el conocimiento de los reveses de la guerra, no resultaría extraño que un ejército de considerables dimensiones solo pudiera constituirse por un tiempo limitado, siendo por ello necesario que las operaciones militares se realizaran con rapidez, jugándose a veces el destino del país en una batalla (Demélas, 2003, p. 421).

\section{Intentos por reformar la conscripción durante el boom del guano}

Considerando estas razones estratégicas, no es de sorprender que desde mediados de la centuria se hicieran intentos por reformar los medios de obtención de tropas. La inédita estabilidad lograda durante la primera administración de Ramón Castilla (1845-1850) y los crecientes recursos fiscales de los que se empezó a disponer con la comercialización del guano ofrecieron la oportunidad para implementar nuevos mecanismos de alistamiento de soldados que, además de pretender ser más eficientes y confiables, buscaban hacer cumplir los derechos y deberes de los ciudadanos conscriptos. La ley del 4 de enero de 1848 indicaba en sus considerandos que buscaba "evitar los desórdenes y vejaciones que sufren los pueblos por los encargados de practicarlo [el servicio]" y prescribía dos mecanismos para la dotación de tropas.

El primero, el enganche, había sido diseñado como el medio prioritario para llenar las bajas en tiempos de inseguridad como guerra exterior o desórdenes internos.
Consistía en un contrato autorizado por el Gobierno, entre representantes del Estado central (el subprefecto o los gobernadores) y el recluta, por el cual se le abonaba a este último una cantidad de dinero (50 pesos). Una parte del emolumento era entregado a la firma del contrato, mientras que el restante era abonado al término del tiempo del servicio. En la contratación debían encontrarse presentes el síndico, quien como representante de la comunidad cautelaría la voluntariedad y cumplimiento del contrato, así como los jefes de los cuerpos que demandaban altas, a fin de observar que los reclutas cumplieran requisitos físicos (talla, complexión física y buena salud), buscando evitar así el ingreso de soldados "inaparentes para el servicio". Para militares como Juan Espinoza, el enganche era un método "más racional de aumentar las filas", pues tenía dos ventajas adicionales sobre la leva: primero, permitía purgar de las poblaciones a los elementos negativos para las misma, en tanto solo "vagos, ociosos y hombres inútiles que no saben ganar su vida [con un oficio]" aceptarían enrolarse en el ejército; segundo, era mucho más conveniente para el Ejército aquellos que voluntariamente se "hacen el ánimo á correr todos los azares de una buena ó mala fortuna" en la vida de cuartel que aquellos que habían sido forzados (Espinoza, 2001 [1856], p. 381). El enganche era un mecanismo que pretendía establecer una relación directa — por medio del contrato- entre el recluta y el Estado sobre la base de su voluntaria fuerza humana; sin embargo, este no siempre revestía las formalidades del caso, pues a veces los enganchadores "invita[ba]n a los jóvenes a beber y una vez embriagados tratan de convencerlos de sentar plaza" (Middendorf, 1973, p. 270).

El segundo mecanismo fue un reformado proceso de conscripción. Con la finalidad de ofrecer mayores garantías a la población, estipulaba la ley que en cada distrito debía formarse una junta de notables locales, integrada por autoridades —el síndico y el cura de la parroquia- y cuatro padres de familia "honrados", los cuales debían elegir a los conscriptos primero entre los elementos perjudiciales de la comunidad (los considerados "vagos"), individuos que "no tengan ocupacion ni se ejerciten en alguna industria ni sean utiles a sus familias", y en el caso de que no se completasen las altas, correspondía realizar un sorteo entre todos los solteros de 18 a 40 años de edad. La norma excluía a los individuos que practicaban oficios liberales, a los hijos de padres de ancianos y de viudas, a los alumnos de escuelas, a los sirvientes conocidos de las iglesias, a los mayorales y camayos, a los yanaconas de hacienda y chacras, y a los operarios de minas. Asimismo, "[l]os transeuntes de cualquier procedencia y los indígenas contribuyentes no deb[ía]n entrar en el sorteo". 
Sin embargo, a pesar de los esfuerzos de esta nueva legislación, estos mecanismos terminaron siendo un fracaso. En 1860, año en el que el Perú libraba una guerra contra el Ecuador y el Ejército bordeaba los once mil efectivos, se denunció en la prensa una serie de casos de reclutamiento, ya no en las lejanas áreas rurales, sino en la misma capital del país ${ }^{5}$. Ese mismo año, en una presentación ante el Parlamento, el ministro de Guerra y Marina se lamentaba de la dificultad de reemplazar a los efectivos militares por medio del enganche:

SIENDO casi general la repugnancia que hay en el pais para servir en las filas, la aplicacion de la ley de 4 de Enero de 1848, no ha podido dejar de encontrar embarazos en su ejecución. [...] el de enganche á mas de dispendioso es ineficaz [cursivas del autor]; porque necesitándose de un fuerte incentivo para vencer la resistencia que se tiene á enrolarse en el Ejército, és menester que sea muy alto el premio del enganche, y aun asi los reemplazos que se obtienen son en corto número y muy paulatinamente. (Ministerio de Guerra y Marina, 1861, p. 19).

La entrega de la conscripción a las élites o notables locales ("honradas"), sin control del Estado central, permitía el uso arbitrario de esta atribución en los departamentos, como daba cuenta un alarmado ministro de Guerra dos años después:

[Cuando] se ha pedido á los Departamentos algun contingente para aumentar la fuerza, las autoridades han representado la ineficácia de ella y el mal éxito de su ejercicio. En algunos pueblos, las personas llamadas á intervenir en el sorteo, designan á su arbitrio los individuos que deban salir para el servicio, y las mas de las veces escojen hombres exceptuados por la ley ó inaparentes, ocasionando males á las familias y gastos inútiles al Estado, pues es raro que de diez hombres, por ejemplo, de los que mandan, se hallen tres con las calidades necesarias para el servicio militar. (Ministerio de Guerra y Marina, 1862, p. 62)

Afirmaba el ministro que el gobierno había dictado diferentes medidas:

Para impedir este desórden, y hasta ha llegado á prohibir la conscripcion algunas veces [...] con todo ni ha podido conseguirse el objeto, ni evitarse que algunas autoridades, por el mal ejercicio de sus funciones, manden como conscriptos á individuos que la suerte no señaló, ó como vagos perjudiciales al vecindario á personas con las cuales tienen algun motivo particular de disgusto. Tales procedimientos [...] dan oríjen al falso concepto de que el Gobierno ordena el reclutamiento forzado.
Estos actos acontecen en lugares distantes, muchos pasan desapercibidos [...] (Ministerio de Guerra y Marina, 1862, p. 62)

Diversos testimonios contradecían las afirmaciones del ministro de Guerra y Marina. En julio de 1861, se denunciaban en Camaná (departamento de Arequipa) el ejercicio arbitrario de la leva, reclamándose que "de una vez y por siempre, y en cumplimiento de Constitución deje de haber reclutaje en esa provincia". La leva era "esa langosta que tala los campos, de ese granizo que destruye las sementeras, de esa peste que deja desiertos los talleres" (El Comercio, 3 de julio de 1861). El servicio de las armas no se extendía universalmente sobre todos los grupos sociales y étnicos de manera equitativa, pesaba sobre los mestizos, afrodescendientes $y$, especialmente, sobre los indígenas. Un artículo escrito en ese contexto de denuncias frente a la leva, titulado "Carta de indemnidad para la leva", sentenciaba que para escapar de este apremio era necesario ser o parecer blanco y mostrar signos de riqueza, así sea "una cadena de fierro galvanizado, que pueda pasar por oro legítimo". Por el contrario, quienes no tenían escapatoria de esta carga eran los indígenas:

¡Ay del indio que labra la tierra, apacenta los ganados, arrea las asemilas y las llamas! Ó del menestral laborioso si caen en una patrulla! La casaca los hará soldados, un clima estraño e insalubre los llevará á un hospital; ni sus pobres esposas ni sus pobres hijos sabrán donde murieron para pagar con sus lágrimas los restos mortales de los seres que los amaron (EI Comercio, 6 de noviembre de 1861).

Estos mecanismos no acabaron con la leva, esta se había convertido en una práctica fuertemente arraigada en la cultura militar decimonónica; por el contrario, su fracaso, reafirmaron su ejercicio. Es por ello que durante el gobierno de Manuel Pardo y Lavalle (1872-1876) se buscó modificar nuevamente la legislación de conscripción, en un escenario político favorable para una reforma del Ejército. Desde la década de 1860, existían fuertes críticas al predominio de los militares sobre el gobierno del país y por extensión a las instituciones militares —entre ellas, la conscripción y la leva-, críticas que se arreciaron con el fracaso del golpe de Estado de los hermanos Gutiérrez contra el flamante presidente Pardo y que terminó con el ajustamiento público de tres de ellos (Velásquez, 2013, pp. 99-104; Mc Evoy, 1997, pp. 103-104). 
Entre las diversas normas que expidió en relación con el Ejército peruano, Pardo promulgó la ley de conscripción de 1872, que ordenaba el alistamiento general de los ciudadanos para el reemplazo de los licenciados y bajas de un Ejército permanente fijado en tres mil hombres. La norma proscribía la prelación sobre los "vagos" de las localidades y prescribía, por primera vez en la historia republicana, que, de manera universal, igualitaria y obligatoria, se realizara un sorteo entre los jóvenes comprendidos entre los 21 y 24 años de edad, excluyéndose a los profesionales, religiosos, estudiantes y familiares de parientes en estado de necesidad, a semejanza de la norma de 1848. No mencionaba nada acerca de los indígenas tributarios (categoría que legalmente ya no existía) ni de los yanaconas. Una importante novedad fue entregar el proceso de conscripción íntegro a las municipalidades — provinciales y distritales-y a la comunidad local, así como dictaminar que el sorteo se verificase en la plaza pública para evitar el uso arbitrario de la institución. De esta manera, Pardo -contrariamente a sus objetivos - reafirmaba el control (arbitrario) de las élites locales sobre el proceso de conscripción, dejando al Gobierno central casi excluido del proceso, al corresponderle solo establecer el número de ciudadanos que debía entregar cada localidad, mientras que la única responsabilidad de los funcionarios militares era la de incorporar al conscripto a las filas del cuerpo militar asignado (Ley del 20 de noviembre de 1872).

El Gobierno también intentó regularizar de manera más precisa los procedimientos de enganche. El 25 de septiembre de 1872 expidió un modelo de contrato por el cual se debía formalizar el enganche, especificándose el sueldo del solado, los períodos de descanso, la pena en el caso de deserción, los beneficios militares y el período del servicio al que se comprometía, el cual era de dos años. Para garantizar la ausencia de coerción en la suscripción del acto, se incluía una constancia firmada por el enganchado por la que se comprometía "libre y voluntariamente á vivir en el batallón [...] sujetándome á las condiciones determinadas en la presente". Debían expedirse dos copias del contrato, una entregada inmediatamente al enganchado — quien podía ser una persona iletrada - y otra quedaba archivada en el cuerpo al que se daba de alta al nuevo soldado ( $E I$ Comercio, 25 de septiembre de 1872).
En el esquema planteado por la administración de Pardo, de manera inversa a lo establecido por Castilla, la conscripción debía ser el mecanismo primario para llenar las bajas del Ejército, en tanto se basaba en un deber que debía pesar universalmente sobre todos los ciudadanos hábiles de la nación; mientras que al enganche solo le correspondía un rol subsidiario destinado principalmente a la contrata de las clases (suboficiales, es decir, cabos y sargentos) (Ibíd). Si bien estos fueron los deseos de la República práctica de Pardo, diversos indicios dan cuenta de que los objetivos de la reforma tampoco se alcanzaron en esta ocasión. Las bajas del Ejército, en alguna medida, fueron reemplazadas mediante el enganche (Pardo, 2004, p. 468), pero ante la situación de inestabilidad política generada por la oposición armada de Nicolás de Piérola, en varias provincias del país, como Puno y Cusco, el Gobierno recurrió al viejo y conocido método del reclutamiento (Mücke, 2010, pp. 276-277). Completaron las fuerzas gobiernistas las Guardias Nacionales ${ }^{6}$, cuerpos milicianos liderados por prominentes miembros del Partido Civil y compuestos por sectores medios y populares urbanos. Sin duda, Pardo antes que en el Ejército, confió en que la Guardia Nacional sería un antemural frente un nuevo intento de golpe de Estado promovido por los militares desafectos a un gobierno civil, prestando mayor resolución gubernamental a las milicias que a la conscripción (Villanueva, 1973, p. 25; Hidalgo et al., 2005, pp. 183-186).

\section{La Guerra del Pacífico y la conscripción de la población indígena}

Pocos años más tarde sobrevino la aciaga Guerra del Pacífico (1879-1883), conflicto que mostró con elocuente claridad los límites del Estado caudillista y del poco profesionalizado Ejército peruano. Aunque muchos militares de oficio y ciudadanos dieron su vida en defensa del país, lo cierto es que, ante esta suprema prueba para medir la solidez de las instituciones peruanas, el Ejército como organización falló irremisiblemente, con la secuela de la pérdida de los territorios de Tarapacá y Arica. Mucho se ha discutido acerca de las debilidades

6 Las Guardias Nacionales fueron cuerpos milicianos que durante la historia decimonónica complementaron al ejército permanente. Por lo general, eran fuerzas no acuarteladas de origen urbano, compuestas por los vecinos que se organizaban solo ante situaciones excepcionales de guerra. No formaban parte del Ejército, escogían a sus propios jefes y solo entrenaban una vez a la semana, si es que lo hacían. 
del Ejército peruano como parte de las causas de la derrota, refiriéndose los historiadores a la falta de armamento, politización y falta de profesionalismo de los oficiales, entre otros. Resulta claro que los mecanismos y prácticas de conscripción preexistentes fueron empleados en esta guerra y, por tanto, tuvieron su cuota de responsabilidad en el desenlace del conflicto.

Durante los cuatro años que duró la guerra, políticos y militares peruanos crearon continuamente ejércitos para enfrentar a las fuerzas chilenas, combinando las prácticas de levantamiento de tropas antes mencionadas. Al iniciar el conflicto en 1879, sobre la base original de 5241 soldados del ejército de línea (Milla Batres, 1980, p. 193), se alistaron de manera voluntaria diversos ciudadanos - jóvenes y adultos-, como individuos o como parte de corporaciones, fuera en los cuerpos del Ejército o como milicianos en las Guardias Nacionales ${ }^{7}$. Cuando el ejército del sur fue derrotado y la guerra tocó las puertas de Lima, se dieron diversos decretos para la conscripción de los limeños (Comisión Permanente de Historia del Ejército, 1981, pp. 57-60), así como se trajeron a la capital soldados levados, conscriptos y enrolados en las haciendas, en su mayoría, indígenas provenientes de la sierra (Ayacucho, Junín y Pasco) (Manrique, 1988, pp. 27-28; Palomino, 2014, pp. 392-396). En el caso de la capital, es de comprender que la inminencia de la conflagración en las puertas de la ciudad no dejaba más alternativa que el luchar para defender su ciudad, su familia y sus intereses ${ }^{8}$; sin embargo, para quienes venían conscriptos, levados o enrolados por pactos específicos, el grado de compromiso para con el conflicto era diferente, como fue el caso de muchos soldados indígenas. Fue así que, a pesar de que Nicolás de Piérola se autoproclamó "Protector de la raza indígena" para legitimar el llamado del Estado a la población indígena para servir en el ejército (Palomino, 2013, p. 393), resultaba palpable que la lealtad a la causa de una patria con la cual contaban vínculos que solo exigían cargas y ausencia de derechos, sería sin duda precaria. En una carta que escribió Ricardo Palma a Nicolás de Piérola, luego de la derrota en San Juan y Miraflores en enero de 1881, el tradicionista sentenció, no sin rencor y decepción lo siguiente:

En mi concepto, la causa principal del gran desastre del 13 está que la mayoría del Perú la forma una raza abyecta y degradada que usted quiso dignificar y ennoblecer. El indio no tiene el sentimiento de la patria; es enemigo nato del blanco y del hombre de la costa y, señor por señor, tanto le da ser chileno como turco. Así me explico que batallones enteros hubieran arrojado sus armas en San Juan, sin quemar una cápsula. Educar al indio, inspirarle patriotismo, será obra no de las instituciones, sino de los tiempos. (Palma, 1964, p. 20)

No era una sentencia carente de asidero, varios testigos de la campaña de Lima coincidían en la ausencia de sentido de pertenencia a la nación peruana de los soldados indígenas. Carey Brenton afirmaba que los soldados indios:

Desconocían totalmente las causas por la cual luchaban, imaginándose que se trataba de una revolución en la que los contendientes estaban comandados respectivamente por los generales Chile y Piérola. También me contó un oficial que había oído decir a los soldados que "ellos no se iban a dejar matar por la causa de los blancos" [...] Se desconoce el esprit de corps, y aunque el soldado peruano lanza invariablemente el grito de “iViva el Perú!", ya sea antes de atacar o antes de huir del enemigo, es probable que no conozca su significado y grite meramente porque se le ha ordenado hacerlo [...]. (Wu Brading, 1984, p. 92)

Teniendo en cuenta la debilidad de las instituciones de conscripción, resulta fácil comprender que, ante lo apremiante de la situación, la derrota fuera causada por la acelerada constitución de estas tropas sucedida por una frenética instrucción de soldados. En un conocido pasaje de sus Impresiones de un reservista, Manuel González Prada recordaba que luego de la derrota en la batalla de San Juan "[a]lgunos pobres indios de la sierra (morochucos, según dijeron) llevaban rifles nuevos, sin estrenar; pero de tal modo ignoraban su manejo que pretendían meter la cápsula por la boca del arma". El mismo González Prada mencionaba que los contingentes traídos de la sierra y los conscriptos de la capital poco habían entrenado con armas de fuego y que, por el contrario, los ejercicios doctrinales en los pocos meses de los que se dispusieron se dedicaron a solo al entrenamiento de la marcha (González Prada, 2009, pp. 450, 452).

Una situación totalmente diferente se observó durante la Campaña de la Breña, protagonizada principalmente por las montoneras indígenas capitaneadas por Andrés

7 Mariano Paz Soldán menciona que "[c]onsolador y tierno era el entusiasmo desplegado en Lima para prepararse a combatir contra el enemigo; antiguos magistrados y hombres públicos que habían sido ministros de estos, jueces y abogados; ricos propietarios, comerciantes acaudalados, artesanos laboriosos, profesores de colegios y universidades, estudiantes, todos sin distinción se enrolaron gustosos en los diversos cuerpos que componían la reserva [...]" (Paz Soldán, 1979, t. II, p. 220).

8 González Prada menciona que, inicialmente, los citadinos se presentaron resueltos y confiados a las prácticas de la reserva para la defensa de la capital (González Prada, 2009, pp. 449-450). 
Avelino Cáceres. El balance de la participación de la población indígena en este enfrentamiento es bastante distinto. Los campesinos de los pueblos de Junín, Huancavelica y Ayacucho fueron fuerzas auxiliares que hicieron posibles las exitosas operaciones de los batallones de Cáceres y sus acciones militares recibieron el elogio de propios y extraños, por su arrojo en el combate, compromiso con sus jefes $y$, por supuesto, las victorias que salvaban el maltrecho honor nacional ${ }^{9}$. Lo cierto era que Cáceres, hijo de una familia hacendada de Ayacucho, con ascendencia noble indígena, conocía el imaginario campesino y logró durante gran parte de la campaña su adhesión y lealtad. Esta reposaba en un pacto o alianza basada en trato respetuoso a los campesinos (los montoneros llamaban a Cáceres "tayta"), el reconocimiento de sus propios liderazgos, la promesa de justicia y, luego, la persecución de intereses propios de los campesinos, como la recuperación de sus tierras apropiadas por terratenientes rivales o su ampliación en detrimento de las de estos últimos. La guerra les ofreció a estos campesinos la oportunidad de contar con armas de guerra que emplearon para atacar a las fuerzas chilenas y a los colaboradores locales que fueron principalmente terratenientes rivales (Manrique, 1988, pp. 43-44, 49, 56-57; Pereyra, 2015).

Desde el punto de vista del Ejército y de la guerra, esta forma de participación en el conflicto mostraba una vez más la utilidad ofensiva de fuerzas irregulares nacidas por negociaciones particulares entre jefes militares $y$ campesinos indígenas: lo atestiguan las victorias militares de Concepción, Marcavalle y Pucará; pero, al mismo tiempo, puso de manifiesto el nivel de autonomía que podían alcanzar sus miembros, quienes dispusieron de armas para sus propios intereses. El propio Cáceres notó esta creciente autonomía que atentaba contra el planteamiento estratégico de la campaña y resquebrajaba el orden social terrateniente de las sociedades agrarias serranas del centro y el sur. Por ello, reprimió duramente a los líderes que desobedecieron sus órdenes y tomaban tierras de los terratenientes (Manrique, 1988, pp. 56-57).

\section{El servicio militar obligatorio y la civilización de los indígenas}

Los esfuerzos colectivos de Cáceres, sus generales breñeros y las montoneras no fueron suficientes para lograr una rendición más favorable para el Perú, por lo que el propio Cáceres tuvo que aceptar el Tratado de Ancón (1883) como un hecho consumado. La derrota en la malhadada guerra, no solo significó la pérdida de territorios, sino también el agravamiento de una crisis económica iniciada en la década anterior, la erosión de las capacidades administrativas y coercitivas del Estado, y el agravamiento de conflictos sociales y étnicos preexistentes. Este ambiente enrarecido, fruto de la derrota, fue la oportunidad para desarrollar una serie de reflexiones y reformas encaminadas a restablecer la vida del país, las que dieron inicio al período conocido como la Reconstrucción Nacional (1883-1895). El Ejército y las formas de conscripción no fueron la excepción durante este período que coincidió con el gobierno de los militares acerados en las breñas, desarrollando una corriente de opinión favorable a la militarización del país, como una forma de evitar un nuevo desastre militar. Así, en uno de los artículos de la Revista Military Naval, órgano de publicidad del Centro Militar, se podía leer la siguiente convocatoria al país: “Después de los desastres experimentados en la última guerra nacional [...] Trabajemos pues en este sentido [prepararse para la guerra] y pongamos los medios para que echen raíces que desarrollen en todas las clases sociales las virtudes militares" (1888, n. ${ }^{\circ} 3$, p. 33).

Concordante con este discurso, el gobierno de Cáceres promulgó en 1887 una ley que reformaba la Guardia Nacional, transformándola en la reserva del ejército permanente, es decir, una fuente de conscriptos cuando las fuerzas del Ejército los requiriesen y como unidades tácticas plenas integradas al Ejército nacional ante el contexto de una guerra internacional. La ley prescribía que todos los ciudadanos que no estuvieran exceptuados por cláusulas taxativas debían inscribirse en un registro provincial ad hoc. Prescribía también que en cada departamento se crease una Asamblea de la Guardia Nacional, compuesta por oficiales del Ejército - como representantes del Gobierno central- encargados de efectuar el registro de la población apta para el servicio, organizar los cuerpos e instruirlos periódicamente (ley del 15 de octubre de 1887).

Para los gobiernos del Segundo Militarismo, la militarización del país no solo tenía funciones estratégicas, sino también debían convertirse en un instrumento de "civilización" de los indígenas, mediante su incorporación al

9 Cáceres afirmaba respecto a los guerrilleros indígenas que en su "espíritu habían operado una transacción radical las torturas a que estaban condenados, convirtiéndolos en huestes guerreras sedientas de sangre chilena [...]. Por todas partes se levantaron enormes masas de gente decididas al sacrificio, invocando quizá si por primera vez el sagrado nombre de la Patria, que comenzaban a echar de menos, bajo la opresión de sus verdugos, en sus atropellos, en sus familias" (Guzmán et al., 2010, p. 103). 
Ejército. Muy a tono con el indigenismo de la posguerra (Toche, 2008, p. 38), no escapó a estos jefes militares el plantear que los indígenas podían obtener, al interior de los cuerpos del Ejército, la instrucción civil elemental que no habían recibido en sus poblaciones, haciéndolos así ciudadanos occidentalizados, útiles para la nación:

El Ejército [es] un medio eficaz de civilización tal vez el único para las masas peruanas. Poderoso elemento de civilización difunde la luz de la instrucción entre los indígenas, devolviendo al cabo de algún tiempo [...] á individuos que recibe en bruto; millares son los que con el trato continuo de camaradas ya civilizados, cambio de lugares, aprendizaje de lengua castellana y los rudimentos de la Enseñanza Elemental dada en los cuarteles, han despertado del letargo en que la más supina ignorancia los postrara [...] transformados en miembros útiles para la República. (Revista Militar y Naval, 1891, n. ${ }^{8} 87$, p. 2027) ${ }^{10}$

Si bien la ley buscaba tener alcances universales, sus logros son poco claros. Por un lado, las cifras de inscritos en los registros fueron verdaderamente importantes. Para 1891, el ministro de Guerra y Marina reportaba que alcanzaban los 72561 ciudadanos, mientras que un año después la cifra se había elevado a 76 711. Asimismo, para este último año, se informaba haberse formado once asambleas departamentales que supervisaban la instrucción en el papel de 151 batallones de infantería, 17 regimientos de caballería y 2 de artillería (Ministerio de Guerra y Marina, 1891, cuadro Guardia Nacional de la República, s/n; 1892, 8). Estas augurantes cifras contrastaban con las continuas demandas oficiales para el aumento de un presupuesto destinado a las funciones de esta institución. Desde 1888, el inspector de la Guardia Nacional, el coronel Justiniano Borgoño, solicitaba el incremento de los recursos, considerando que 80000 soles eran insuficientes para el pago de oficiales instructores de alta graduación, idóneos para la organización e instrucción de los milicianos (Ministerio de Guerra y Marina, 1888, p. 6). Restricciones presupuestarias similares hacían informar al ministro, en 1892, que no se contaba con el personal de instrucción militar suficiente para todos los cuerpos del país (Ministerio de Guerra y Marina 1892, p. 7; también Ministerio de Guerra y Marina, 1893, XIII); situación que a la larga limitaría la capacidad del Estado central de ejercer de manera directa la conscripción en el amplio del país.
El Segundo Militarismo terminó con la guerra civil de 1895, por la cual los militares dejaron el poder. La derrota de los hombres de Cáceres a manos de milicianos y montoneros liderados por Nicolás de Piérola mostró una vez más que las instituciones militares, a pesar de los esfuerzos hechos en la postguerra, no podían sostener al Gobierno y que distaban mucho de ser un baluarte contra amenazas a la integridad territorial. Y, de hecho, lo más preocupante para Piérola y la coalición política civil que lo acompañó durante su mandato resultaba ser la persistente vocación de los militares por ejercer el gobierno del país. Estas razones motivaron al Califa a emprender una reforma sustancial del Ejército que fue la base de su profesionalización, acompañado de una misión militar compuesta por jóvenes oficiales franceses.

El gobierno de Piérola y las administraciones posteriores dieron importancia capital a la forma de conscripción de ciudadanos. En 1898, se dio una ley del servicio militar obligatorio que buscaba desterrar definitivamente los procedimientos preexistentes para la formación de ejércitos - la leva, las alianzas clientelares, las guardias nacionales y el enganche-, universalizando la conscripción como un deber fundamental de los ciudadanos. La ley prescribía una verdadera militarización de la población, a ejemplo de los ejércitos europeos, organizando a la población en grupos de edad que debían movilizarse consecutivamente ante una situación de guerra.

Pese a que entre 1896-1898 hubo voces que rechazaron el servicio militar universal por considerarlo como contrario a las condiciones sociales y culturales del país, la coalición gobernante veía esta nueva institución como una muestra de progreso y civilización del país (Velásquez 2013, pp. 313-314), siempre y cuando existiera para las clases propietarias la posibilidad de eximirse del servicio activo mediante el pago de una prima (una multa en dinero). Para los legisladores que dieron esta ley, la igualdad en el deber que exigía la ciudadanía, podía cumplirse de manera diferenciada, como lo expresaba el senador y futuro presidente del país, Manuel Candamo:

En el Perú, por la desigualdad de razas, entre las que predomina la de color; y más que eso, por la diferencia de educación, sería poco práctico que se obligara á entrar en el sorteo á jóvenes de distintas condiciones. [...] obligando al servicio obligatorio sin distinción, no solo se hace impracticable la ley,

10 Esta propuesta no era privativa de los militares, era también compartida por miembros de las élites civiles. Nicolás de Piérola escribía en la Declaración de Principios del Partido Demócrata: "El Ejército tiene que ser, al mismo tiempo, en el Perú, aprovechándolo convenientemente al intento, en grande i eficaz medio de civilización para la gran mayoría de nuestro pueblo" (Partido Demócrata, 1889, p. 43). 
sino que se hace un daño al país, porque más vale que hayan diez ó veinte jóvenes estudiantes de medicina, jurisprudencia, literatura; etc., dedicados á su profesión, que vayan al ejército, en donde se les puede remplazar por diez ó veinte de condición distinta [...] El que tiene fortuna cumple sus obligaciones con dinero; es una desgracia para los que no lo tienen, pero es desgracia irremediable. (Cámara de Senadores, 1898, p. 115)

Si este criterio de excepcionalidad de las clases propietarias era un requisito para la aprobación de la reforma, resultaba claro que la conscripción reposaría sobre los sectores populares urbanos y rurales, especialmente sobre la población indígena, la cual, se consideraba, constituía las dos terceras partes de los habitantes del país. El indio debía ser la base de las tropas del Ejército como lo había sido durante toda la centuria. Sin embargo, en este punto no existía necesariamente consenso acerca de la utilidad del indígena para la milicia, pues para algunos militares y civiles, la experiencia había demostrado que no podía esperarse de los indígenas el cumplimiento de este deber ciudadano por las condiciones sociales y culturales en las que vivían y por sus aptitudes morales, produciéndose en la prensa capitalina un interesante debate acerca del soldado indio.

A fines de la centuria, los diagnósticos sobre el indígena coincidían en dos características que se reforzaban mutuamente, a saber: servidumbre e ignorancia. En las descripciones sobre la condición de los indígenas, estos eran presentados como sujetos sometidos a una situación de"servidumbre" por los hacendados, los notables y autoridades locales, la misma que imposibilitaba el ejercicio por sí mismos de sus derechos ciudadanos y obstaculizaba su relación directa con el Estado. Asimismo, eran vistos como desprovistos de educación y cultura, evidentemente occidental, ostentando una ignorancia que los mantenían en una situación de marasmo y de desconocedores de sus derechos, de las bondades de la cultura oficial y de su pertenencia a la nación peruana (Velásquez, 2013, pp. 320-322). Obstruía, sin duda, esta conciencia de peruanidad el abuso de las autoridades locales que mediaban la relación de esta población con el Estado, pues los indígenas no tenían "ni más sentimientos de Patria que el horror á todo lo que emane de los altos Poderes Públicos por el intermedio del atroz Subprefecto o Gobernador" (El Comercio, 25 de febrero de 1898, edición de la tarde). Si los indígenas no eran ciudadanos, no cabía convertirlos en soldados de un ejército reformado y profesional. Así lo consideraba el oficial Tadeo Simeón Antay, quien en 1896 sentenciaba que no existía en esta población compromiso con el destino del país, iniciativa propia, por lo que sería inútil exigir de ellos el cumplimiento cívico del servicio militar:

Con aquellas gentes [la población indígena], educadas en la escuela de la esclavitud y del temor, con las que crecen y se desarrollan bajo el látigo del cacique, con las que no saben pensar ni hablar su idioma ni tienen la más ligera idea de la patria ni de sus propios derechos ¿se puede formar un Ejército? Con hombres que carecen de ideas propias y si las tienen no son de otro sino del cura, gobernador y juez de paz, que los explota ¿se puede organizar un respetable Ejército, según las exigencias de las guerras modernas? ( $E I$ Comercio, 22 de abril de 1896, edición de la tarde)

Otro argumento que se esgrimió en contra de su alistamiento como soldados fue su tendencia hacia la deserción, demostrada en diversos pasajes de la historia decimonónica. Para el oficial Leyva Deustúa, las deserciones que habían ocasionado la derrota de Ingavi en 1841, la deposición de Pezet en 1865 y el desbande de Huamachuco en 1883 eran muestra palpable de que los indígenas constituían un peligro para las armas nacionales, pues:

Las deserciones desmienten la creencia general de que el indio sea sufrido y resignado en la milicia. ¿Y que importan en buena cuenta en sobriedad y resistencia, si bajo la corteza de la mansedumbre, humildad y finta alegría, el melancólico y taciturno suspirador de la quena esconde aladas taloneras, es arisco ante el deber de derramar su sangre por la patria, y al frente del enemigo común imita al ciervo que apercibe al cazador? (El Comercio, 20 de abril de 1898, edición de la tarde)

En contraste, algunas opiniones coincidían en que los indígenas poseían aptitudes físicas y morales que podían explotarse para el bien de la nación y servir de base para convertirlos en adecuados soldados para el Ejército. En un proyecto de instituciones para la protección de las poblaciones indígenas del Partido Constitucional, se atribuía a estas "ricas y poderosas aptitudes morales" $y$, especialmente, una "abnegación y valor heroico que ha demostrado siempre que se ha tratado de la defensa de la honra y de la integridad de la Patria" (La Opinión Nacional, 30 de abril de 1897). Por su parte, el oficial Ignacio Vera Tudela coincidía en esta postura, recordando que gracias a los progresos realizados durante el gobierno de Pezet, se constituyó en dos años un poderoso ejército, en el cual se organizaron academias que permitieron que "toda la tropa aprendi[era] á leer y escribir con otros rudimentos"; se les inculcó "la moral militar", se proscribió "el abuso del licor" y se les ejercitó en gimnasia, "adquiriendo [los soldados] de ese modo la salud, robustez y aire marcial que eran consiguientes". 
Creía Vera Tudela que esfuerzos semejantes realizados por el Gobierno, permitirían "establecer los cimientos que en la práctica pueden llevarnos á un porvenir lisongero y provechoso" (El Comercio, 24 de marzo de 1898, edición de la mañana). Por su parte, el civil Ortiz de la Puente consideraba que los cuarteles no solo darían a los soldados indígenas aptitudes militares, sobre todo, podían ofrecerles el aprendizaje de la lectura y escritura y, con ello, la historia del país que les mostrase "el noble origen de su raza, la accidentada historia de su patria, y los hechos heroicos de sus compatriotas en la última contienda nacional". Este sería un medio eficaz para articular las memorias particulares de sus comunidades en el gran relato de la nación y posibilitaría así la imaginación de una comunidad nacional. Ello permitiría redirigir la lealtad de los indígenas hacia el Estado, por encima de sus comunidades locales, es decir, de su patria chica:

Triste á la vez que elocuente ejemplo se ha dado en la última guerra nacional de su bravura en los casos en que los protagonistas eran jóvenes aguerridos, instruidos en el manejo de las armas y que poseían los simples conocimientos de saber leer y escribir; $y$ de la cobardía de los otros, que huian á los primeros disparos por no tener la menor idea de patria, ni ningún otro conocimiento intelectual y moral que la vida abyecta y de ignorancia que observan en la mísera chosa de sus pueblos y en las tristes é ignotas soledades de la puna. (EI Comercio, 16 de junio de 1898, edición de la mañana)

Resulta interesante rescatar que en este debate los partidarios y detractores sobre las aptitudes de los indígenas como soldados coincidían en que su condición de servidumbre e ignorancia no se debía a factores ingénitos, es decir, no eran propios de la naturaleza de su raza; por el contrario, eran resultado de las condiciones sociales, económicas y culturales, y por tanto, una firme acción del Estado, sea por medio de la educación civil o un servicio militar que ofreciera a la población indígena acceso a la ciudadanía y las competencias culturales necesarias para formar parte de la nación, podría convertirlos en agentes del progreso del país (Velásquez, 2013, pp. 326-328). En este sentido, la mayoría de quienes participaron en este debate se diferenciaron de los debates racialistas que alrededor de la Universidad de San Marcos protagonizó en esas precisas fechas la intelligentsia criolla -representada elocuentemente en la tesis de Clemente Palma, titulada Sobre el porvenir de las razas en el Perú- sobre la utilidad del indio para la nación peruana, desestimando su contribución en el pasado y en el porvenir (Demélas, 2003, pp. 381-388).

Las decisiones tomadas por el gobierno de Nicolás de Piérola y sus sucesores durante la República Aristocrática
(1895-1919) muestran que las posturas racialistas, si bien fueron parte del ambiente cultural de la época, se hacían impracticables en sociedades donde la mayoría de la población pertenecía a aquellas razas consideradas inferiores. El rosto del soldado peruano necesariamente tendría que ser indígena. Es por ello que desde el año 1900, la Ley del Servicio Militar Obligatorio empezó a llamar contingentes de hombres jóvenes entre los 19 y 23 años de edad, en su mayoría indígenas. Sin embargo, resulta interesante observar que la conscripción dejó de ampararse en la leva o en la cesión voluntaria y clientelar de hombres. Por el contario, las reformas del Ejército iniciadas desde fines de la centuria hicieron posible que el Estado exigiese a los habitantes del país el cumplimiento de este deber, a excepción —claro está- de los hijos de las familias acomodadas.

El modelo de conscripción que estableció la ley de 1900 contemplaba la creación de juntas de conscripción provinciales, cuyas funciones consistían en registrar a los ciudadanos en aptitud de llevar las armas, realizar el sorteo de los conscriptos y garantizar que estos cumplieran con los requisitos prescritos por la ley. Si bien entre sus miembros fueron incorporados notables locales, ellos, desde el principio, estuvieron bajo la supervisión de autoridades del Gobierno central, como los subprefectos y gobernadores. Desde el inicio, la aplicación de la ley tropezó - como en el caso de reformas anteriores- con la dificultad de que las autoridades y notables locales cumplieran las disposiciones de la norma y garantizaran los derechos de los ciudadanos, amparados en la virtual inexistencia del Estado en los espacios locales. Resultaba necesaria - como lo mostró la experiencia - la creación de una burocracia militar especial que acompañara el trabajo de las autoridades locales y la confección de los registros, y vigilara el ejercicio del sorteo, así como la idoneidad de los conscriptos, que en su mayor parte eran remitidos a la capital (Velásquez, 2013, pp. 349-353).

El montaje de esta burocracia se inició con la creación de un moderno Estado Mayor General (EMG), en el cual se instaló una sección especial dedicaba a resolver todos los asuntos relativos a la aplicación de la ley del servicio militar. Cupo al jefe de la misión militar francesa, Paul Clément, como subjefe del EMG, hacer el seguimiento de los procedimientos de la conscripción, resolver las reclamaciones de los abusos y dirigir el funcionamiento de comisiones militares destinadas a vigilar in situ el proceder de las juntas de conscripción en las provincias. Este esquema se perfeccionó con la creación de tres estados mayores regionales (norte, centro y sur) -los cuales fueron erigidos para dirigir 
una amplia burocracia militar que se extendía hasta el nivel provincial en casi todos los departamentos del país (solo quedó excluido Loreto)—, cuya tarea era vigilar directamente el cumplimiento impersonal de los procedimientos y perseguir a quienes omitieran la obligación del servicio. Solo con funcionarios militares distribuidos en todo el territorio y dirigidos centralmente desde Lima fue posible, no sin tropiezos, el destierro de las formas antiguas de levantamiento de tropas, y ello permitió que un Estado presente (no abstracto ni lejano) exigiera a los peruanos, como individuos abstractos, el cumplimiento del deber ciudadano, desplazando así todo tipo de intermediario, fueran los hacendados, otros notables locales o las propias comunidades indígenas (Velásquez, 2013, pp. 336-340).

Para concluir, es menester mencionar qué sucedió con la población indígena en este nuevo sistema de conscripción. El indio siguió siendo la base del Ejército peruano, qué duda cabe; sin embargo, las autoridades militares buscaron distribuir de manera equitativa el impuesto de sangre sobre el resto de la población, haciendo el llamamiento a los conscriptos bajo criterios demográficos y de circunscripción territorial, mas no étnicos. El llamamiento se hacía exigiendo una cantidad de conscriptos a cada distrito del país, en función del número de sus habitantes, distribuyéndose de manera proporcional el peso de la conscripción que dejó de estar circunscrita a distritos serranos y rurales. Es cierto que los indígenas darían el rostro al soldado peruano, pero solo en tanto constituían la mayoría del país (más del $50 \%$ del total de acuerdo con el censo de 1876); al lado de ellos, hubo ciudadanos urbanos de diversos grupos étnicos que empezarían a cumplir su deber ciudadano (Velásquez, 2013, pp. 341-343).

Para las comunidades indígenas, esta mayor presencia del Estado, que exigía fuerza de trabajo sin compensación alguna, siguió siendo una molestia, por lo cual desarrollaron múltiples modos de resistirla (Velásquez, 2013, pp. 365-372). Sin embargo, el servir en filas, con el tiempo, ofreció a los soldados - como individuosbeneficios que les permitían mejorar sus condiciones de vida y reclamarse como ciudadanos, aprender los rudimentos de la cultura occidental - como saber leer y escribir, la historia patria-y un oficio remunerado ${ }^{11}$. El precio para ser ciudadanos a principios del siglo $x x$ fue para estos hombres, el servir en el Ejército y occidentalizarse, es decir, primero cumplir deberes y luego, muy luego, gozar los derechos de la ciudadanía.

\section{Reflexiones finales}

El historiar la relación del servicio militar y la población indígena en el siglo xIX nos ofrece la oportunidad de reflexionar acerca del Estado, la ciudadanía y la nación en el Perú. Nuestra experiencia decimonónica muestra con claridad la dificultad de construir relaciones de autoridad, esto es, ciudadanía, en un contexto en el que el Estado está ausente. La posibilidad de cumplir el ordenamiento legal (las leyes de conscripción) de manera universal y directa sobre los individuos abstractos no podía ejercerse sin capacidades administrativas y coercitivas mínimas que hicieran cumplir los mandatos de la ley, incluso a pesar de la renuencia de los sujetos obligados. La solución que se dio a la resistencia campesina fue la leva y la negociación a través de una serie de intermediarios (caudillos militares, jefes militares, élites o notables locales) con intereses propios y que, en su accionar, inhibían la relación que debía existir entre el Estado y sus ciudadanos. De manera inversa, los indígenas no se sentían obligados a entregar voluntariamente su fuerza humana sin contraprestación tangible, en tanto el Estado, ausente en las áreas rurales, no garantizaba derechos ni mucho menos allanaba las asimetrías entre estos y otros grupos étnicos; contravenía su propio ordenamiento legal que tenía como principio de la ciudadanía la igualdad ante la Ley. Sin Estado, no podía existir una nación cívica y, menos, compromiso de los campesinos indígenas, cuya lealtad primera era a sus propias comunidades.

Los actores de finales del siglo xIx resolvieron acabar con este tipo de relación por medio del establecimiento de una ley del servicio militar obligatorio, la cual solo pudo hacerse efectiva cuando se construyó una burocracia que permitía el cumplimiento universal e impersonal de la conscripción. Su proyecto, al mismo tiempo, buscó construir la ciudadanía, la ansiada ciudadanización de los indígenas, de una manera paradójica y parcial: otorgaron ciudadanía efectiva solo a aquellos individuos indígenas que previamente servían y al precio de occidentalizarse.

11 En un sugerente ensayo, Cecilia Méndez llamó la atención acerca de los diversos casos en los que indígenas licenciados del Ejército se convertían en líderes de las comunidades campesinas en sus luchas contra los gamonales durante las dos primeras décadas del siglo xx (Méndez, 2006, pp. 29-30). 


\section{Referencias}

Cámara de Senadores. (1898). Diario de los debates de la Honorable Cámara de Senadores. Congreso Estraordinario de 1898. Lima: Imprenta de "El Comercio".

CONTRERAS, C. (2004). El aprendizaje del capitalismo. Estudios de historia económica y social del Perú republicano. Lima: Instituto de Estudios Peruanos.

EspinozA, J. (2001 [1856]). Diccionario republicano. Edición y estudios preliminar por Carmen Mc Evoy. Lima: Pontificia Universidad Católica del Perú, Universitas of the South-Swanee.

GonzÁlez Prada, M. (2009). ¡Los jóvenes a la obra! Textos esenciales. Lima: Fondo Editorial del Congreso del Perú.

Mc Evor, C. (2004). La huella republicana liberal en el Perú. Manuel Pardo. Escritos fundamentales. Lima: Fondo Editorial del Congreso del Perú.

Mc Evor, C. (2015). La guerra maldita. Domingo Nieto y su correspondencia (1834-1844) (t. I). Lima: Biblioteca Nacional del Perú.

MÉnDEZ, C. (2004). Tradiciones liberales en los Andes: militares y campesinos en la formación del Estado peruano. Recuperado de http://www.tau.ac.il/eial/ XV_1/mendez.html

Méndez, C. (2014). La república plebeya. Huanta y la formación del Estado peruano, 1820-1850. Lima: Instituto de Estudios Peruanos.

MIDDENDORF, E. W. (1973). Perú. Observaciones y estudios del país y sus habitantes durante una permanencia de 25 años. Lima: Universidad Nacional Mayor de San Marcos.

Ministerio de GuerRa y Marina. (1849). Memoria presentada a las Cámaras reunidas en sesiones ordinarias en 1849 por el Ministro de Guerra y Marina. Lima: Imprenta de José M. Masías.

Ministerio de GuerRa y MARINA. (1861). Memoria que el Ministro de Estado en el despacho de Guerra y Marina presenta al Congreso. Lima: Tipografía de Aurelio Alfaro y Cía.

Ministerio de GuerRa y MaRina. (1862). Memoria que presenta el Ministro en el despacho de Guerra y Marina al Congreso Nacional de 1862. Lima: Imprenta de la Época.

Ministerio de GuerRa y Marina. (1888). Memoria que presenta al Congreso Ordinario de 1888 el Ministro de Estado en el despacho de Guerra y Marina, Elías Mujica. Lima: Imp. de Torres Aguirre.

Ministerio de GUeRRA Y MARINA. (1891). Memoria que el Ministro de Guerra y Marina presenta al Congreso Ordinario de 1891. Lima: Imprenta Liberal de F. Masías y Ca.

Ministerio de Guerra y Marina. (1892). Memoria que el Ministro de Guerra y Marina presenta al Congreso Ordinario de 1892. Lima: Imprenta liberal de F. Masías y Ca.

Ministerio de GuerRa y Marina. (1893). Memoria que el Ministro de Guerra y Marina presenta al Congreso Ordinario de 1893. Ramo de Guerra. Lima: Imprenta del Centro Militar.

PALmA, R. (1964). Cartas a Piérola (2. a ed.). Lima: Editorial Milla Batres.

PAZ-SoldÁn, M. (1979). Narración histórica de la guerra de Chile contra el Perú y Bolivia [edición y epígrafes Carlos Milla Batres]. Lima: Editorial Milla Batres.

Sartiges E. -de y De-Botmiliau, A. (2012). Dos viajeros franceses en el Perú Republicano. Lima: Instituto Raúl Porras Barrenechea.

Wu BrAdINng, C. (1984). Testimonios británicos de la ocupación chilena de Lima. Lima: Editorial Milla Batres. 


\section{Bibliografía}

A suovín, C. (2000). Caudillos y Constituciones. Perú, 1821-1845. Lima: Pontificia Universidad Católica del Perú. Instituto Riva-Agüero / México, D. F.: Fondo de Cultura Económica.

Aısovín, C. (2005). Sufragio y participación política. Perú 1808-1896. En C. Aljovín y S. López (Eds.), Historia de las elecciones en el Perú. Estudios sobre el gobierno representativo. Lima: Instituto de Estudios Peruanos.

BASADRE, J. (2003). La iniciación de la República. Lima: Universidad Nacional Mayor de San Marcos.

Chiaramonti, G. (2005). Ciudadanía y representación en el Perú, 1808-1860: los itinerarios de la soberanía. Lima: Universidad Nacional Mayor de San Marcos.

Comisión Permanente de Historia del EjérCito (1981). La Gesta de Lima 1881 -13/15 de enero-1981. Lima: CPHE.

Demélas, M.-D. (2003). La invención política. Bolivia, Ecuador, Perú en el siglo xix. Lima: Instituto de Estudios Peruanos, Instituto Francés de Estudios Andinos.

Del Águlta, A. (2013). La ciudadanía corporativa: política, constituciones y sufragio en el Perú (1821-1896). Lima: Instituto de Estudios Peruanos.

Flores Galindo, A. (2008 [1988]). Obras Completas III (I). Buscando un inca. Lima: Sur Casa de Estudios del Socialismo.

GuzMÁn, L. ET Al. (2010). La primera memoria de Cáceres y otros documentos relativos a la Campaña de la Breña (18811889). Lima: Orden de la Legión Mariscal Cáceres-Universidad Alas Peruanas.

HIDALGO, T. et Al. (2005). Historia del Ejército en la República. Siglo xIx. La institucionalización del ejército: organización y evolución (t. V, vol. 1). Lima: Comisión Permanente de la Historia del Ejército del Perú (CPHEP).

MAnRIQUe, N. (1988). Yawar mayu. Sociedades terratenientes serranas 1879-1910. Lima: Instituto Francés de Estudios Andinos, Centro de Estudios y Promoción del Desarrollo.

Mc Evor, C. (1997). La utopía republicana: ideales y realidades en la formación de la cultura política peruana (1871-1919). Lima: Pontificia Universidad Católica del Perú.

MÉNDEZ, C. (2006). Las paradojas del autoritarismo: ejército, campesinado y etnicidad en el Perú, siglos XIX y xx. Íconos. Revista de Ciencias Sociales, 26.

Milla Batres, C. (ED.). (1980). Recopilación de partes y documentos de la Guerra del Pacífico: 1879-1883. Edición conmemorativa del primer centenario de la guerra del 79. Lima: Milla Batres.

MücKE, U. (2010). Política y burguesía en el Perú: el Partido Civil antes de la guerra con Chile. Lima: Instituto Francés de Estudios Andinos, Instituto de Estudios Peruanos.

NúÑEZ, F. (2005). La participación electoral indígena bajo la Constitución de Cádiz (1812-1814). En C. Aljovín y S. López (Eds.), Historia de las elecciones en el Perú. Estudios sobre el gobierno representativo. Lima: Instituto de Estudios Peruanos.

Palomino, O. (enero del 2014). La participación de los indígenas durante la Guerra con Chile: Controversias historiográficas. Nueva corónica, (3), 391-401.

Pereyra, N. (2015). Los campesinos de Ayacucho y la Guerra del Pacífico. Reflexiones desde (y sobre) la teoría de los estudios subalternos. Diálogo Andino. Revista de Historia, Geografía y Cultura Andina, (48), 31- 40.

Quiroz, F. (1992). Los curacas de Huarochirí y su presencia en las guerrillas de la Independencia y los primeros años de la República (1750-1830). En Huarochirí: ocho mil años de historia. Lima: Municipalidad de Santa Eulalia de Acopaya.

Remy, M.-I. (diciembre de 1988). La sociedad local al inicio de la República. Cusco 1824-1850. Revista Andina, 6(2), 451-484. 
TocHE, E. (2008). Guerra y democracia. Los militares peruanos y la construcción nacional. Lima: Centro de Estudios y Promoción del Desarrollo, Consejo Latinoamericano de Ciencias Sociales.

Tristán, F. (2005). Peregrinaciones de una paria. Lima: Centro de la Mujer Peruana Flora Tristán, Universidad Nacional Mayor de San Marcos.

VelÁsquez, D. (2013). La reforma militar y el gobierno de Nicolás de Piérola. El ejército moderno y la construcción del Estado peruano (tesis de magíster). Universidad Nacional Mayor de San Marcos.

VILlanUeVA, V. (1973). Ejército peruano: del caudillismo anárquico al militarismo reformista. Lima: Mejía Baca.

Walker, Ch. (2004). De Túpac Amaru a Gamarra. Cusco y la formación del Perú republicano. 1780-1840 (2. ed.). Cusco: Centro de Estudios Rurales Bartolomé de Las Casas.

\section{Periódicos y revistas}

El Comercio (Lima): 1860-1861, 1872, 1896-1898.

La Opinión Nacional (Lima): 1897.

Revista Militar y Naval (Lima): 1888-1891. 